\title{
Multiple $G_{i}$ proteins participate in nerve growth factor-induced activation of c-Jun N-terminal kinases in PC12 cells
}

Prudence H. Tso, Christina J. Morris, Lisa Y. Yung, Nancy Y. Ip, Yung H. Wong*

Department of Biochemistry, the Molecular Neuroscience Center, and the Biotechnology Research Institute, Hong Kong University of Science and Technology, Clear Water Bay, Kowloon, Hong Kong, China.

* To whom correspondence should be addressed. Department of Biochemistry, Hong Kong University of Science and Technology, Clear Water Bay, Kowloon, Hong Kong, China.

Tel: $\quad+85223587328$

Fax: $\quad+85223581552$

e-mail: boyung@ust.hk

Running Title: Role of $\mathrm{G}_{\mathrm{i} / \mathrm{o}}$ Proteins in NGF-Induced Stimulation of JNK 


\section{ABSTRACT}

Nerve growth factor (NGF)-mediated activation of mitogen-activated protein kinases (MAPK) is critical for differentiation and apoptosis of PC12 cells. Since NGF employs stress-activated c-Jun N-terminal kinase (JNK) to regulate both programmed cell death and neurite outgrowth of PC12 cells, we examined NGF-regulated JNK activity and the role of $\mathrm{G}_{\mathrm{i} / \mathrm{o}}$ proteins. Induction of JNK phosphorylation by NGF occurred in a time- and dosedependent manner and was partially inhibited by pertussis toxin (PTX). To discern the participation of various signaling intermediates, PC12 cells were treated with specific inhibitors prior to NGF challenge. NGF-elevated JNK activity was abolished by inhibitors of JNK, p38 MAPK, Src, JAK3 and MEK1/2. NGF-dependent JNK phosphorylation became insensitive to PTX treatment upon transient expressions of $\mathrm{G} \alpha_{z}$ or the PTX-resistant mutants of $\mathrm{G \alpha}_{\mathrm{i1}-3}$ and $\mathrm{G} \alpha_{\mathrm{oA}}$. Collectively, these studies indicate that NGF-dependent JNK activity may be mediated via $\mathrm{G}_{\text {i1-3 }}$ proteins, JAK3, Src, p38 MAPK and the MEK/ERK cascade.

\section{KEYWORDS}

Nerve growth factor, c-Jun N-terminal kinase, $\mathrm{G}_{\mathrm{i} / \mathrm{o}}$ proteins, PC12 pheochromocytoma cells, neurite outgrowth, Trk-A receptor 


\section{INTRODUCTION}

The mitogen-activated protein kinase (MAPK) superfamily plays a critical role in apoptosis and axonal outgrowth of the rat PC12 pheochromocytoma cells (1-3). Nerve growth factor (NGF) can activate all three members of MAPKs in PC12 cells. The dynamic balance between the activities of extracellular signal-regulated protein kinase1/2 (ERK1/2), c-Jun Nterminal kinases (JNKs) and p38 MAPK appears to be a critical factor in the regulation of neurite outgrowth and programmed cell death (4-6). ERK1/2 and p38 MAPK have been extensively studied for their roles in the differentiation of PC12 cells by NGF $(5,7)$, whereas the activity of JNK is often examined in the context of apoptosis $(8,9)$.

There is increasing evidence to suggest that JNK activity is required for neuritogenesis. JNK signaling is apparently required for the differentiation of SH-SY5Y neuroblastomas (10), embryonic midbrain cells (11), neural progenitor cells (12) and PC12 cells (13). Moreover, JNK is thought to participate in neurite outgrowth of N1E-115 neuroblastoma cells (14), dopaminergic neuronal cells (15) and PC12 cells (16). It has been reported that NGF induces transient activation of JNK1 and JNK2 in PC12 cells (4). Two groups have further demonstrated that JNK activation is essential for NGF-induced neuritogenesis of PC12 cells $(3,17)$. Interestingly, JNK3 is an effector in both neuronal differentiation and cell death of PC12 cells (18). It is obvious that JNK activity is essential for both apoptosis and differentiation of PC12 cells. However, the actual signaling intermediates in JNK pathway involved in regulation of both cellular processes upon NGF stimulation are less clear.

Regulation of neuronal differentiation is not an exclusive feature of growth factors. There is now a substantial body of literature indicating that neurotransmitters acting on G protein-coupled receptors (GPCR) play a role in neuronal differentiation. Although the pathways involved in GPCR-triggered neurite outgrowth are not fully understood, many of these receptors utilize pertussis toxin (PTX)-sensitive $\mathrm{G}_{\mathrm{i} / \mathrm{o}}$ proteins for signal transduction. N1E-115, LA-N-5, Neuro2A and PC12 cells appear to employ $G_{0}$ to mediate neurite 
outgrowth (19-22). Neurite outgrowth stimulation by $\mathrm{G}_{\mathrm{i} / \mathrm{o}}$-coupled receptors is thought to be mediated via a signaling network that comprises of the small GTPases Rap1, Ral and Rac, the protein kinases Src, JNK, and signal transducer and activator of transcription 3 (STAT3) (23).

Interestingly, signals arising from receptor tyrosine kinases and $\mathrm{G}_{\mathrm{i} / \mathrm{o}}$-coupled receptors are capable of integrating at the level of MAPKs (24). In PC12 cells, platelet-derived growth factor (PDGF) and NGF have been reported to utilize $G_{\mathrm{i} / \mathrm{o}}$ signaling pathways to phosphorylate ERK1/2, and that these pathways require clathrin-mediated endocytosis and phosphoinositide 3-kinase (PI3K) activation (25-27). In addition, NGF-induced ERK1/2 phosphorylation involves G protein-coupled receptor kinase 2 (GRK2) and $\beta$-arrestin 1 (27). The involvement of $\mathrm{G}_{\mathrm{i} / \mathrm{o}}$ proteins in NGF-induced ERK1/2 phosphorylation and neurite outgrowth in PC12 cells is well established, whereas their contributions to the NGF-JNK pathway are less clear.

In the present study, we investigated the signaling intermediates that are required for NGF-stimulated JNK activity in PC12 cells. The signaling intermediates examined included individual members of the $\mathrm{G}_{\mathrm{i} / \mathrm{o}}$ superfamily as well as molecular components along the phospholipase C (PLC), JAK/STAT, and PI3K/Akt pathways. Our results indicated that NGF-induced JNK phosphorylation in PC12 cells was partially mediated via PTX-sensitive $\mathrm{G}_{\mathrm{i} / \mathrm{o}}$ proteins and was suppressed in the presence of inhibitors against JNK, JAK3, p38 MAPK, Src and ERK1/2. Functional associations of the NGF receptor, TrkA, with $\mathrm{G \alpha}_{\mathrm{i1}-3}$, $\mathrm{G} \alpha_{\mathrm{oA}}$ and $\mathrm{G} \alpha_{\mathrm{z}}$ were demonstrated with the use of $\mathrm{G} \alpha$ subunit mutants.

\section{EXPERIMENTAL PROCEDURE}

Materials. The rat $\mathrm{G}_{\mathrm{z}}$ cDNA was a gift from Dr. Y. Kaziro (Tokyo Institute of

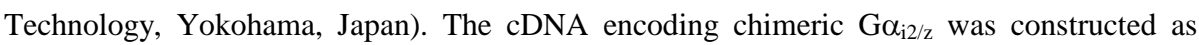
described previously (28). The $\mathrm{G} \alpha_{\mathrm{oA}} \mathrm{CI}$ and $\mathrm{G} \alpha_{\mathrm{i1}-3} \mathrm{CI}$ cDNAs were obtained from Guthrie 
(Sayre, PA, US). PC12 cells were obtained from American Type Culture Collection (ATCC CRL-1721; Rockville, MD). PTX and mouse NGF (mNGF 2.5S grade 2) were obtained from List Biological Laboratories (Campbell, CA) and Alomone labs (Jerusalem, Israel), respectively. WHI-P131, WHI-P258, U0124, AG490, KN62, W7, wortmannin, SB202190, SB203580, U73122, U73343, staurosporine, calphostin C, SU6656, c-Raf-1 inhibitor (5-Iodo3-[(3,5-dibromo-4-hydroxyphenyl) methylene]-2-indolinone), U0126, Anthra[1,9-cd]pyrazol6(2H)-one 1,9-pyrazoloanthrone SAPK/JNK inhibitor II (SP600125), N1-Methyl-1,9pyrazoloanthrone SAPK Inhibitor II (420123), epidermal growth factor receptor inhibitor (AG1478), PDGF receptor blocker (AG1295), PP1, PP2 and PP3 were obtained from Calbiochem (San Diego, CA). Antisera against JNK and phospho-JNK $\left(\mathrm{Thr}^{183} / \mathrm{Tyr}^{185}\right.$ ), were purchased from Cell Signaling Technology, (Beverly, MA). Cell culture reagents were obtained from Invitrogen (Carlsbad, CA) and all other chemicals were purchased from Sigma Chemical (St. Louis, MO).

Cell culture and transfection. PC12 cells were cultured in Dulbecco's modified Eagle's medium (DMEM) supplemented with 6\% fetal calf serum (FCS; v/v), 6\% horse serum (HS) (v/v), $50 \mathrm{U} / \mathrm{ml}$ penicillin and $50 \mu \mathrm{g} / \mathrm{ml}$ streptomycin at $37^{\circ} \mathrm{C}$ in humidified air with $7.5 \% \mathrm{CO}_{2}$. PC12 cells were seeded onto 12 -well plates at a density of $3 \times 10^{5}$ cells/well in $1 \mathrm{ml}$ of growth medium. 24 h later, PC12 cells were transiently transfected with Qiagenpurified cDNAs (0.5 $\mu$ g of $\mathrm{G} \alpha_{z}, \mathrm{G}_{\mathrm{z}} \mathrm{QL}, \mathrm{G} \alpha_{\mathrm{oA}}, \mathrm{G} \alpha_{\mathrm{oA}} \mathrm{CI}, \mathrm{G} \alpha_{\mathrm{i} 1-3}, \mathrm{G} \alpha_{\mathrm{i} 1-3} \mathrm{CI}, \mathrm{G} \alpha_{\mathrm{i} 2 / \mathrm{z}}$ or pcDNA1) using LipofectAMINE 2000 according to the manufacturer's instructions. For transient transfection, 2\% FCS DMEM without penicillin and streptomycin instead of serum free DMEM was used to culture the PC12 cells. After transfection, PC12 cells were maintained in DMEM containing 6\% FCS and 6\% HS for $24 \mathrm{~h}$ prior to JNK assay.

Primary cortical neuron cultures were prepared from embryonic day 18 (E18) rat embryos. Cortices were dissected in DMEM, dissociated in the same medium, and plated on 
poly-D-lysine coated culture plates. Cells were cultured in neurobasal medium containing B27 supplement, $0.5 \mathrm{mM}$ glutamine, penicillin (50 units $/ \mathrm{ml})$, and streptomycin $(100 \mu \mathrm{g} / \mathrm{ml})$. Cultures were incubated at $37^{\circ} \mathrm{C}$ in a humidified atmosphere with $5 \% \mathrm{CO}_{2}$.

JNK assay. PC12 cells were cultured overnight with DMEM containing 0.1\% FCS in the presence or absence of $100 \mathrm{ng} / \mathrm{ml}$ PTX. The cells were stimulated with or without various inhibitors for 15 min and subsequently with or without different concentrations of NGF for 1$30 \mathrm{~min}$ as indicated. Cell lysates were collected with $150 \mu \mathrm{l}$ of $2 \%$ SDS sample buffer (50 mM Tris-Cl, 100 mM dithiothreitol, 2\% SDS, 0.1\% bromophenol blue, 10\% glycerol; $\mathrm{pH}$ 6.8). $80 \mu \mathrm{l}$ of each cell lysate was resolved by $12 \%$ SDS-polyacrylamide gel electrophoresis, and then transferred to nitrocellulose membranes. The presence of total JNK and phospho-JNK were detected by anti-JNK and phospho-JNK $\left(\mathrm{Thr}^{183} / \mathrm{Tyr}^{185}\right)$, respectively. Immune complexes were detected with horseradish peroxidase-conjugated secondary antibodies. Immunoblots were developed in the presence of enhanced chemiluminescence reagents, and the images detected in X-ray films were quantified by densitometric scanning using the Eagle Eye II still video system (Stratagene, La Jolla, CA). Values shown represent the mean \pm S.E. from three or more separate experiments. Representative blots were selected from a set of three independent experiments.

\section{RESULTS}

JAK3, Src, ERK1/2 and p38 MAPK are involved in NGF-induced JNK activity. We began our study by examining the effect of a variety of kinase inhibitors on NGF-induced neurite extension in PC12 cells. As compared to the control, PC12 cells treated with NGF (5 ng/ml, 10 days) exhibited numerous protrusions of neurites (Fig. 1A). The NGF-induced neurite extension was, however, significantly suppressed when cells were exposed to either a MEK1/2 inhibitor (U0126, $10 \mu \mathrm{M})$, the JNK/p38 inhibitor SB202190 $(10 \mu \mathrm{M})$, or to the 
specific JNK inhibitor SP600125 (10 $\mu \mathrm{M})$ (Fig. 1A, B), suggesting that JNK might participate in NGF-induced neuronal differentiation. The ability of NGF to activate JNK in PC12 cells was then determined using anti-phospho-JNK antibodies. As illustrated in Fig. 1, NGF stimulated the activity of JNK in a time- and dose-dependent manner. When PC12 cells were challenged with either 5 or $50 \mathrm{ng} / \mathrm{ml}$ NGF for various time durations, activation of JNK was detected as early as 5 min of incubation and reached peak activity at around 10 min (Fig. 1C). The JNK phosphorylation was maximally elevated by $~ 4.5$ - to 6-fold above the basal level and sustained for up to 30 min (Fig. 1C). At the optimum incubation time of $10 \mathrm{~min}$, treatment of PC12 cells with increasing concentrations of NGF resulted in a dose-dependent stimulation of JNK (Fig. 1D). The activity of JNK reached a maximum of $\sim 8$ - to $\sim 9$-fold above the basal level when the NGF concentration was at $50 \mathrm{ng} / \mathrm{ml}$ or higher. The NGFinduced onset and maximum phosphorylation of JNK in PC12 cells were consistent with previous studies $(17,29)$.

To map the signaling pathways linking TrkA receptor activation to JNK in PC12 cells, a panel of inhibitors was tested against NGF-induced JNK phosphorylation. Since JNK plays an essential role in cell survival (2), NGF may utilize signaling intermediates of the Ras/MAPK, JAK/STAT, and PI3K/Akt pathways, all of which contribute to cell survival, to regulate the activity of JNK. First, we examined the role of the Ras/Raf-1/ERK1/2 cascades in NGF-regulated JNK activity because ERK1/2 and JNK activities appear to be essential for differentiation of PC12 cells $(3,17)$. As expected, treatment of PC12 cells with SP600125 (10 $\mu \mathrm{M})$, but not its inactive analogue $420123(24 \mu \mathrm{M})$, completely blocked the NGF-induced JNK phosphorylation (Fig. 2A). A 15 min incubation of PC12 cells with either the MEK1/2 inhibitor U0126 $(10 \mu \mathrm{M})$, the JNK/p38 MAPK inhibitor SB202190 $(10 \mu \mathrm{M})$, or a more specific inhibitor of p38 MAPK, (SB203580, $10 \mu \mathrm{M}$ ), significantly attenuated the NGFinduced JNK phosphorylation (Fig. 2B). The level of suppression by the MEK1/2 and p38 
MAPK inhibitors was similar to that obtained with the JNK inhibitor (Fig. 2A, B). Similar incubation with either the inactive analogue of U0126 (U0124, $10 \mu \mathrm{M}$ ) or the Raf-1 kinase inhibitor (5-Iodo-3-[(3,5-dibromo-4-hydroxyphenyl) methylene]-2-indolinone, $10 \mu \mathrm{M}$ ) however, did not exhibit any effect (Fig. 2B). Functional inhibition of NGF-induced phosphorylation of ERK by U0126 was demonstrated in separate experiments (data not shown). Whereas NGF-induced ERK phosphorylation was abolished by the Raf-1 kinase inhibitor, U0124 had no effect on NGF-induced ERK activity (data not shown). Thus, these results demonstrated that a Ras/Raf-independent activation of ERK1/2 and p38 MAPK was essential for NGF-mediated JNK phosphorylation.

It has been well established that PI3K is involved in NGF-mediated survival of sympathetic neurons and contributes in part to the neurite outgrowth initiation processes (30) as well as activation of ERK1/2 (31). However, addition of the PI3K inhibitor, wortmannin (100 nM), to PC12 cells for 15 min had no effect on NGF-stimulated JNK activity (Fig. 3A). Inhibition of PI3K by wortmannin was confirmed by the loss of NGF-induced phosphorylation of Akt (data not shown). Thus, NGF-dependent JNK phosphorylation in PC12 cells required the activity of ERK1/2 but not PI3K.

To examine whether JAK is involved in NGF-regulated JNK, PC12 cells were treated with or without $10 \mu \mathrm{M}$ WHI-P131, a specific JAK3 inhibitor, for 15 min prior to stimulation by NGF (5 ng/ml). Inhibition of JAK3 attenuated NGF-induced JNK phosphorylation by 85\% (Fig. 3B). In contrast, the inactive analogue of WHI-P131 (WHI-P258, $10 \mu \mathrm{M}$ ) and inhibition of JAK2 with $100 \mu \mathrm{M}$ AG490 for 15 min did not affect the ability of NGF to induce JNK phosphorylation (Fig. 3B; data not shown). Likewise, addition of specific inhibitors for the receptors of PDGF (AG1295, $10 \mu \mathrm{M}$ ) or EGF (AG1478, $50 \mathrm{nM}$ ) to PC12 cells was unable to inhibit NGF-stimulated JNK phosphorylation (Fig. 3A; data not shown), suggesting that G protein-mediated transactivation of EGF or PDGF receptors was not 
involved in NGF-induced activation of JNK. Thus, these results suggest that NGF utilized JAK3 to regulate JNK activity in PC12 cells.

A series of studies have revealed that PC12 cell differentiation involves activation of PKC via tyrosine phosphorylation by c-Src $(32,33)$. Hence, the roles of c-Src and PKC in NGF-induced JNK phosphorylation in PC12 cells were also investigated. Blockade of c-Src activity by treating PC12 cells with different Src inhibitors (PP1, $25 \mu \mathrm{M}$; PP2, $25 \mu \mathrm{M}$; and SU6656, $5 \mu \mathrm{M}$ ) for 15 min substantially attenuated NGF-dependent JNK phosphorylation by approximately 45-55\% (Fig. 3B), while treatment of PC12 cells with inhibitors against PKC (staurosporine, $200 \mathrm{nM}$; calphostin C, $100 \mathrm{nM}$ ) (Fig. 3A and data not shown) for the same time period had no effect on NGF-induced JNK phosphorylation. The inhibitory effect of PP2 was specific because its inactive analogue, PP3, was without effect (Fig. 3B). To visually demonstrate the effect of the JAK3 and Src inhibitors on NGF-induced neurite extension, PC12 cells were treated as described above. The NGF-induced neurite extension was, as expected, significantly suppressed when cells were exposed to either WHI-P131 (10 $\mu \mathrm{M})$ or PP1 (25 $\mu \mathrm{M})$ (Fig. 3C, D).

It seemed then that c-Src, but not PKC, was required for NGF-mediated JNK phosphorylation. Src is a common signaling intermediate for receptor tyrosine kinases that can also be directly stimulated by activated $G \alpha_{i}$ (34). We have previously demonstrated in COS-7 cells that NGF-induced activation of Src requires PTX-sensitive G proteins (35). In PC12 cells, PTX was able to significantly attenuate NGF-increased JNK activity by 50\% (Fig. 4A). Thus, elimination of both NGF-activated Src and JNK activities by pretreatment with PTX, implicates the involvement of $\mathrm{G}_{\mathrm{i} / \mathrm{o}}$ proteins in an NGF-Src-JNK pathway.

Given that NGF-induced activations of ERK (27) and JNK (Fig. 4A) both appeared to involve PTX-sensitive $G_{i / o}$ proteins, the two pathways might share some common signaling intermediates. In CHO cells expressing TrkA receptors, NGF-elicited ERK1/2 
phosphorylation is inhibited by U73122, an inhibitor of PLC (36). Likewise, a number of studies have shown that $\mathrm{Ca}^{2+}$-dependent calmodulin kinase II (CaMKII) participates in neurite outgrowth (37) and in nicotine-induced ERK1/2 phosphorylation in PC12 cells (38). We thus asked if PLC and CaMKII are also involved in NGF-induced stimulation of JNK. However, the addition of inhibitors against PLC (U73122, $10 \mu \mathrm{M}$, or its inactive analogue U73343, 10 $\mu \mathrm{M})$ or against CaMKII (10 $\mu \mathrm{M}$ KN62 or $50 \mathrm{nM}$ W7) to PC12 cells for 15 min had no effect on the ability of NGF to phosphorylate JNK (Fig. 3A). These results implied that both PLC and CaMKII were dispensable in the activation of JNK by NGF. Therefore, in PC12 cells, NGF-stimulated JNK activity was primarily mediated via $\mathrm{G}_{\mathrm{i} / \mathrm{o}}$ protein, JAK3, Src, ERK1/2 and 38 MAPK.

NGF-induced stimulation of JNK was partly mediated via PTX-sensitive $G_{i 1-3}$ proteins. NGF-induced neurite outgrowth of PC12 cells and JNK activity involve $\mathrm{G}_{\mathrm{i} / \mathrm{o}}$ proteins. NGF-induced (5 ng/ml NGF, $10 \mathrm{~min}$ ) stimulation of JNK phosphorylation was significantly attenuated ( 45\%) by pre-incubation of PC12 cells with PTX (100 ng/ml, $24 \mathrm{~h})$ as compared with phosphorylation of JNK in cells without PTX exposure (Fig. 4A). Similarly, NGF-induced (5 ng/ml NGF, 15 min) phosphorylation of JNK in primary cortical neurons was sensitive to PTX treatment_(Fig. 4B). Interestingly, in cortical neurons strong preferential phosphorylation of the p54-JNK isoform, as compared with p46-JNK, was observed (Fig. 4B). As PC12 cells are known to express several forms of $\mathrm{G}_{\mathrm{i} / \mathrm{o}}$ proteins (21), we attempted to determine the role of individual $\mathrm{G}_{\mathrm{i} / \mathrm{o}}$ proteins in NGF-regulated JNK activity. Since many $G_{i / 0}$-coupled receptors utilize $G_{z}$ for signal transduction (39), we also asked if this PTXinsensitive member of the $G_{i}$ family could participate in NGF-induced stimulation of JNK. In PC12 cells transiently expressing $G \alpha_{z}$, stimulation of JNK by NGF became insensitive to PTX treatment (Fig. 4C). Transfection of PC12 cells with the constitutively active form of $G \alpha_{z}\left(G \alpha_{z} Q L\right)$ had no effect on NGF-induced phosphorylation of JNK in the absence or 
presence of PTX (data not shown), presumably because $G \alpha_{z} \mathrm{QL}$ could not associate with its upstream regulator in its GTP-bound active state. One of the approaches to assess the possible involvement of individual PTX-sensitive $\mathrm{G}_{\mathrm{i} / \mathrm{o}}$ proteins in a signaling pathway was to employ PTX-resistant mutants of the $G_{i / o}$ proteins. Provision of PTX-resistant $G_{i / o}$ mutants could confer PTX-resistance to the signaling pathway if the $\mathrm{G}_{\mathrm{i} / \mathrm{o}}$ protein was indeed involved in the signal transduction. A PTX-resistant $G \alpha_{\mathrm{i} 2} / \mathrm{G \alpha}_{\mathrm{z}}$ chimera $\left(\mathrm{G} \alpha_{\mathrm{i} 2 / \mathrm{z}}\right)$ and point mutants of $\mathrm{G}_{\mathrm{i} 1}$ $\left(\mathrm{G} \alpha_{\mathrm{i} 1} \mathrm{CI}\right), \mathrm{G} \alpha_{\mathrm{i} 3}\left(\mathrm{G} \alpha_{\mathrm{i} 3} \mathrm{CI}\right)$ and $\mathrm{G} \alpha_{\mathrm{oA}}\left(\mathrm{G} \alpha_{\mathrm{oA}} \mathrm{CI}\right)$, have previously been successfully employed to study functional associations between $\mathrm{G}$ protein-coupled receptors and mutants of $\mathrm{G \alpha}_{\mathrm{i} / \mathrm{o}}$ subunits, respectively $(28,40,41)$. In PC12 cells transfected with the cDNA of $G \alpha_{\mathrm{i} 2 / \mathrm{z}}$, the NGF-induced JNK phosphorylation became completely PTX-insensitive (Fig. 4C); approximately 6-fold induction of JNK phosphorylation was observed in the absence or presence of PTX treatment. Expression of wild-type $\mathrm{G \alpha}_{\mathrm{i} 2}$ in PC12 cells did not confer PTX resistance to the NGF response (Fig. 4C); the NGF response was suppressed by $\sim 65 \%$ after PTX treatment. Similar results were obtained with the $\mathrm{G} \alpha_{\mathrm{i} 1} \mathrm{CI}, \mathrm{G} \alpha_{\mathrm{i} 3} \mathrm{CI}$ and $\mathrm{G} \alpha_{\mathrm{oA}} \mathrm{CI}$ mutants (Fig. 4C, D). The NGF-induced JNK phosphorylation was completely insensitive to PTX treatment in PC12 cells expressing the $\mathrm{G} \alpha_{\mathrm{i} 1} \mathrm{CI}, \mathrm{G} \alpha_{\mathrm{i} 3} \mathrm{CI}$ or $\mathrm{G} \alpha_{\mathrm{oA}} \mathrm{CI}$ mutants, whereas the same response was significantly attenuated $(\sim 50-80 \%)$ by PTX in cells transfected with cDNA encoding wild-type $\mathrm{G} \alpha_{\mathrm{i} 1}, \mathrm{G} \alpha_{\mathrm{i} 3}$ or $\mathrm{G} \alpha_{\mathrm{oA}}$ (Fig. $\underline{4 \mathrm{C}}, \underline{\mathrm{D}}$ ). These experiments suggested that $\mathrm{G} \alpha_{\mathrm{i} 1} \mathrm{CI}, \mathrm{G} \alpha_{\mathrm{i} 3} \mathrm{CI}, \mathrm{G} \alpha_{\mathrm{i} 2 / \mathrm{z}}$ and $\mathrm{G} \alpha_{\mathrm{oA}} \mathrm{CI}$ could mediate activation signals from NGF. It should be noted that transient expression of each distinct G $\alpha$ subunit in PC12 cells did not affect the ability of NGF to induce JNK phosphorylation (Fig. 4C, D upper panels). Collectively, these results indicate that NGF could utilize PTX-resistant $G_{z}$, PTX-sensitive $G_{0 A}$ and $G_{i 1-3}$ in PC12 cells to regulate JNK activity.

\section{DISCUSSION}


G protein-coupled receptors and receptor tyrosine kinases represent two of the largest families of cell surface receptors and both receptor families utilize highly sophisticated signaling networks with numerous loci for cross-talk (24). One such locus for signal integration is the MAPK cascade. Activation of JNK has been reported to participate in neuronal differentiation and NGF-deprivation induced apoptosis of PC12 cells $(2,17,18)$. Based on the sensitivity of NGF-induced phosphorylation of JNK to PTX, the present study demonstrates the involvement of $\mathrm{G}_{\mathrm{i} / \mathrm{o}}$ proteins in TrkA-mediated JNK activation. This conclusion is further supported by our demonstration that expression of PTX-resistant versions of selected G $\alpha$ subunits can confer total PTX resistance to the NGF-induced response and preliminary studies that indicate $\mathrm{G \alpha}_{\mathrm{i} 1-3}$ can be co-immunoprecipitated with the TrkA receptor (41 and our unpublished observations). These findings are in agreement with the PTX-induced abrogation of NGF-mediated ERK signaling previously observed in PC12 cells (27).

Some of the signaling intermediates engaged in NGF-induced JNK activation in PC12 cells were elucidated in the present study. Inhibitors against JAK3, p38 MAPK, MEK1/2 and Src were as effective as the JNK-selective inhibitors. It is the first time to discover that NGF utilizes JAK3 to regulate JNK activity. SB203580 abolishes p38 MAPK activity by inhibiting MAPKAP kinase 2, a common downstream signaling effector of p38 MAPK and ERK. The requirement for MAPKAP kinase 2 and MEK1/2 implies the involvement of p38 MAPK and ERK1/2 in NGF-induced JNK activation. Elevated cAMP levels also induce, neurite outgrowth of PC12 cells via transactivation of epidermal growth and TrkA receptors (42). Thus the ERK1/2/p38 MAPK-MAPKAP kinase 2 and cAMP pathways provide possible loci for signal integration of TrkA receptor and $\mathrm{G}_{\mathrm{i} / \mathrm{o}}$ proteins.

Deleted: Indeed, the activity of JAK engages differentiation of PC12 cells (42).

Deleted: In addition to JNK (presen study), NGF can utilize both ERK1/2 and p38 MAPK pathways to phosphorylate CREB $\operatorname{Ser}^{133}$ (43). Also, a

Deleted: ne

Deleted: s

Deleted: 44 
Despite the requirement for MEK/ERK activity, NGF-induced JNK activation appeared to be independent of c-Raf-1, reflecting a lack of involvement of the typical Ras/Raf-1/MEK/ERK pathway. TrkA may employ alternative pathways to activate ERK. In

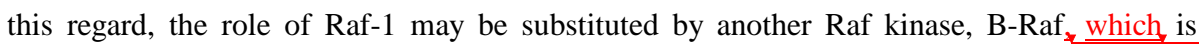
activated by the Ras-like small GTPase Rap1. It is noteworthy that $G \alpha_{0}$ has been shown to activate ERK via B-Raf (45). Moreover, $\mathrm{G \alpha}_{\mathrm{i} 2}$ has been shown to mediate growth of LLC$\mathrm{PK}_{1}$ renal epithelial cells by a Raf-1-independent activation of ERK1/2 (46). The PTXsensitive $G_{i / o}$ proteins are thus perfectly positioned to transduce the signal from TrkA to the Rap1/B-Raf/MEK/ERK pathway. Additional experiments are required to confirm if this postulation is indeed correct. It is also noteworthy that the $\mathrm{G}_{\mathrm{i} / \mathrm{o}}$-coupled sst2 somatostatin receptor has been shown to activate ERK2 via a Src-dependent but Raf-1-independent pathway (47).

In addition, we have presented evidence that Src kinase is involved in NGF-induced JNK activation. The phosphorylation of JNK elicited by NGF was significantly inhibited by specific Src inhibitors, More interestingly, NGF-induced Src activation appeared to be routed through $\mathrm{G}_{\mathrm{i} / \mathrm{o}}$ proteins since Src phosphorylation was PTX-sensitive (41). Activation of Src family kinases is known to play a role in $G$ protein-regulated signaling pathways (48). $G_{i}$ proteins can activate Src directly via $G \alpha_{i}(34)$ or indirectly through $G \beta \gamma$-mediated binding of $\beta$-arrestin (49)._. Moreover, many $\mathrm{G}_{\mathrm{i}}$-coupled receptors can stimulate JNK in a Src-dependent manner (35). The involvement of Src downstream of $G_{i}$ proteins provides the means to activate JNK, probably via the small GTPases Rac and Cdc42 and then MKK3/6 (50). And the activity Rac/Cdc42 protein is required for the neurite outgrowth of PC12 cells (44). Given that Src can bind to both TrkA and $\mathrm{G \alpha}_{\mathrm{i1-3}}$, it may subserve the role of an adaptor in addition to being an effector of TrkA and $\mathrm{G \alpha}_{\mathrm{i1-3}}$. 
Despite the fact that both Raf-1 and PI3K are critical components in NGF-induced neuronal differentiation and survival $(25, \underline{51})$, neither appears to be essential for the activation of JNK by NGF (Fig. 2, 3). TrkA has recently been shown to co-immunoprecipitate with calmodulin from PC12 cell lysates (52), thus raising the possibility that CaMKII may mediate part of the signals generated by NGF. However, inhibition of CaMKII by KN62 had no effect on NGF-induced JNK phosphorylation (Fig. 3A). PLC, calmodulin, and PKC signaling molecules lying upstream of or parallel to $\mathrm{CaMKII}_{2}$ also appeared to be dispensable in the activation of JNK by NGF. Hence, in terms of dependency on the PLC/PKC/CaMKII cascade, regulation of JNK by NGF is different from that of ERK activation (53). .

The exact identity of the PTX-sensitive G protein(s) responsible for relaying part of the activation signal from TrkA to JNK has not been fully elucidated. Previous studies have established that $\mathrm{G} \alpha_{\mathrm{oA}}, \mathrm{G} \alpha_{\mathrm{i} 1}$ and $\mathrm{G} \alpha_{\mathrm{i} 2}$ are significantly upregulated in PC12 cells following NGF-induced neuronal differentiation $(20, \underline{\underline{54}})$. Yet, another study revealed that activation of $\mathrm{G}_{\mathrm{z}}$ attenuates PC12 cell differentiation (43). Both PTX-sensitive and -insensitive members of the $\mathrm{G}_{\mathrm{i} / \mathrm{o}}$ subfamily thus appear to directly or indirectly participate in neuronal differentiation of PC12 cells. The ability of $\mathrm{G \alpha}_{\mathrm{i} 1-3}$ to co-immunoprecipitate with TrkA (41 and our unpublished observations) suggests that $\mathrm{G \alpha}_{\mathrm{i1-3}}$ can physically associate with the TrkA receptor, perhaps through adaptor proteins or as part of a macromolecular signaling complex. $G \alpha_{\mathrm{i} 2-3}$ and $\mathrm{G} \alpha_{0}$ participate in the adipocyte differentiation (55). $\mathrm{G} \alpha_{\mathrm{i} 2}$ has previously been reported to interact with pathways required for differentiation of F9 teratocarcinoma cells (56). The activity of $\mathrm{G}_{\mathrm{i} 3}$ is involved in enterocytic differentiation of cell lines derived from human colon adenocarcinomas - HT-29 and Caco-2 (57). And NGF is able to utilize members of the Rho GTPase family including Rac1 and Cdc42 to induce neurogenesis of PC12 cells (58). The association of $\mathrm{G \alpha}_{\mathrm{i} 1-3}$ with the TrkA receptor does not appear to depend on the activation status of TrkA because application of NGF did not affect their interaction (41). Although 
$\mathrm{G} \alpha_{\mathrm{oA}}$ and $\mathrm{G} \alpha_{\mathrm{z}}$ did not precipitate along with TrkA (41), their involvement in NGF-induced JNK activation should not be simply dismissed. Hints of functional involvement of $G \alpha_{\mathrm{OA}}$ and $\mathrm{G}_{\mathrm{z}}$ in NGF-induced signaling can be gleaned from the responses obtained with PC12 cells overexpressing $\mathrm{G} \alpha_{\mathrm{OA}} \mathrm{CI}$ or $\mathrm{G} \alpha_{\mathrm{z}}$. Provision of the PTX-resistant $\mathrm{G} \alpha_{\mathrm{OA}} \mathrm{CI}$ mutant or $\mathrm{G} \alpha_{\mathrm{z}}$ conferred total PTX-resistance to NGF-induced JNK phosphorylation, indicating that these G proteins can functionally replace endogenous $\mathrm{G}_{\mathrm{i} / \mathrm{o}}$ proteins which have been inactivated by the toxin. TrkA receptor may have a higher preference for $\mathrm{G}_{\mathrm{i1}-3}$ in PC12 cells or it may interact with $G_{0 A}$ and $G_{z}$ through a different mechanism. Potential linkages of TrkA receptor to $G_{0 A}$ and $G_{z}$ are especially interesting because these two $G$ proteins are predominately expressed in neural tissues. It should be noted that the functional G protein component which stimulates MAPK activity is likely to be the G $\beta \gamma$ complex rather than the $G \alpha_{\mathrm{i} / 0 / \mathrm{z}}$ subunit. Expression of G $\beta \gamma$ or constitutively active $G \alpha_{q}$ in HEK 293 cells results in the activation of MAPK (도), whereas similar reports have not been documented for any of the constitutively active Ga $\alpha_{i}$ subunits. Although the involvement of G $\beta \gamma$ in NGF-induced MAPK activation has not been vigorously examined, the fact that NGF can employ multiple $G_{i}$ members for signal transduction supports this notion. Identification of the $G_{i}$ protein that is responsible for relaying the PTX-sensitive component of the NGF-induced JNK phosphorylation will require more definitive studies, perhaps using knock-down approaches with siRNA against individual G protein subunits.

Irrespective of which PTX-sensitive G protein is actually activated upon NGF treatment of PC12 cells, a fundamental question relates to how the activation signal is conveyed to the $G$ protein. Reports on the functional interaction between growth factor receptors and $\mathrm{G}_{\mathrm{i} / \mathrm{o}}$ proteins are rapidly accumulating (60-63). For instance, IGF-1 has been shown to activate $G_{i}$ to release the $G \beta \gamma$ complex, which in turn initiates activation of ERK1/2 $(\underline{64}, 65)$. The IGF-1 receptor appears to associate with a signaling complex composed of a 
regulator of G protein signaling (RGS) protein known as Ga interacting protein (GAIP) and

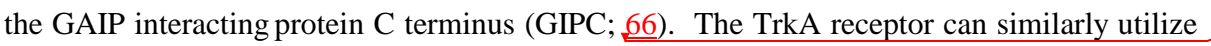
GIPC/GAIP to regulate MAPK. TrkA receptors and GAIP have been shown to simultaneously bind to the PDZ domain of GIPC at different binding sites (67), and overexpression of GIPC reduces NGF-induced ERK1/2 phosphorylation. The association of TrkA receptor with GIPC/GAIP and the inhibition of ERK1/2 activity by GIPC suggest that GIPC may provide a link between TrkA and G protein signaling pathways (67). It is noteworthy that GIPC has been reported to regulate the subcellular distribution of a membrane-associated, neurally enriched member of the semaphorin family of axon guidance signals (68). More intriguingly, NGF can utilize RGS6 to regulate differentiation of PC12 cells (69). TrkA receptors may also behave like PDGF receptors. PDGF receptors are tethered to G protein-regulated signaling pathways by recruitment and activation of GRK2 and $\beta$-arrestin 1 , thus providing a platform on which receptor tyrosine kinase and $G$ protein signals can be integrated to produce more efficient stimulation of MAPK $(27, \underline{70})$. It is noteworthy that $\beta$-arrestin 2 has been identified as a binding partner with JNK3 and acts as a receptor-regulated MAPK scaffold for JNK activation under the control of a GPCR (71). Furthermore, there is increasing evidence for the convergence of signals from RTKs and GPCRs along with the recruitment of scaffolding adaptor proteins that can channel various extracellular stimuli to the phosphorylation of tuberin via the PI3K/Akt pathway (72-74). Particular to NGF, TrkA can be coupled with the PI3K adaptor protein Grb2, the phosphorylation of which is in turn linked to a $\mathrm{G}_{\mathrm{i}}$-coupled receptor (72). Even though these findings do not provide obvious linkages between the TrkA receptor and $\mathrm{G}_{\mathrm{i} / \mathrm{o}}$ proteins, they strengthen the possibility that $G$ proteins do indeed participate in mediating NGF-induced signals.
Deleted: 72

Deleted: $s$
Deleted: 73

Deleted: 73

Deleted: 74

Deleted: 75

Deleted: 76 
Although the present study reveals that NGF employs a multitude of intermediates including $\mathrm{G}_{\mathrm{i1}-3}$ proteins, c-Src, p38 MAPK and ERK1/2 to activate JNK in PC12 cells, the map of signal routing is far from complete. The linkage between G proteins and JNK certainly needs further mapping. Among the obvious candidates are the small GTPases such as Cdc42, Rac and Rho that are known to be activated by NGF (75). Additionally, NGFinduced neurite outgrowth of PC12 cells requires Rap1, Rap1 GTPase activating protein and Deleted: 77 $\underline{\text { Ras-like small GTPase Rin }(43,44)}$. These small GTPases may act as a point of convergence for both TrkA receptors and $\mathrm{G}_{\mathrm{i} / \mathrm{o}}$ proteins. Like many crucial biological processes, complexity in the coordination of neuronal differentiation ensures that the course of action can proceed despite minor defects. Collectively, our present study demonstrated that NGF was able to utilize $\mathrm{G \alpha}_{\mathrm{i1}-3}$, JAK3, Src, ERK1/2 and p38 MAPK to induce JNK phosphorylation. Also, JNK activity was essential for neurite outgrowth of PC12 cells. 


\section{ACKNOWLEDGEMENTS}

This work was supported in part by grants from the Research Grants Council of Hong Kong (HKUST 3/03C), the University Grants Committee (AoE/B-15/01), and the Hong Kong Jockey Club. NYI and YHW were recipients of the Croucher Senior Research Fellowship. 


\section{REFERENCES}

1. Fukuda M, Gotoh Y, Tachibana T et al (1995) Induction of neurite outgrowth by MAP kinase in PC12 cells. Oncogene 11:239-244

2. Xia Z, Dickens M, Raingeaud J et al (1995) Opposing effects of ERK and JNK-p38 MAP kinases on apoptosis. Science 270:1326-1331

3. Waetzig V, Herdegen T (2003) The concerted signaling of ERK1/2 and JNKs is essential for PC12 cell neuritogenesis and converges at the level of target proteins. Mol. Cell. Neurosci. 24:238-249

4. Leppa S, Saffrich R, Ansorge W et al (1998) Differential regulation of c-Jun by ERK and JNK during PC12 cell differentiation. EMBO J. 17:4404-4413

5. Morooka T, Nishida E (1998) Requirement of p38 mitogen-activated protein kinase for neuronal differentiation in PC12 cells. J. Biol. Chem. 273:24285-24288

6. Santos SD, Verveer PJ, Bastiaens PI (2007) Growth factor-induced MAPK network topology shapes Erk response determining PC-12 cell fate. Nat. Cell Biol. 9:324-330

7. Deak M, Clifton AD, Lucocq LM et al (1998) Mitogen- and stress-activated protein kinase1 (MSK1) is directly activated by MAPK and SAPK2/p38, and may mediate activation of CREB. EMBO J. 17:4426-4441

8. Eilers A, Whitfield J, Babij C et al (1998) Role of the Jun kinase pathway in the regulation of c-Jun expression and apoptosis in sympathetic neurons. J. Neurosci. 18:1713-1724

9. Maroney AC, Glicksman MA, Basma AN et al (1998) Motorneuron apoptosis is blocked by CEP-1347 (KT 7515), a novel inhibitor of the JNK signaling pathway. J. Neurosci. 18:104-111

10. Yu YM, Han PL, Lee JK (2003) JNK pathway is required for retinoic acid-induced neurite outgrowth of human neuroblastoma, SH-SY5Y. Neuroreport 14:941-945 
11. Park KS, Lee RD, Kang SK et al (2004) Neuronal differentiation of embryonic midbrain cells by upregulation of peroxisome proliferator-activated receptor- $\gamma$ via the JNKdependent pathway. Expt. Cell Res. 297:424-433

12. Kim SJ, Son TG, Kim K et al (2007) Interferon-gamma promotes differentiation of neural progenitor cells via the JNK pathway. Neurochem. Res. 32:1399-1406

13. Eriksson M, Taskinen M, Leppa S (2007) Mitogen activated protein kinase-dependent activation of c-Jun and c-Fos is required for neuronal differentiation but not for growth and stress response in PC12 cells. J. Cell Physiol. 210:538-548

14. Yamauchi J, Miyamoto Y, Murabe M et al (2007) Gadd45a, the gene induced by the mood stabilizer valproic acid, regulates neurite outgrowth through JNK and the substrate paxillin in N1E-115 neuroblastoma cells. Expt. Cell Res. 313:1886-1896

15. Eom DS, Choi WS, Ji S et al (2005) Activation of c-Jun N-terminal kinase is required for neurite outgrowth of dopaminergic neuronal cells. Neuroreport 16:823-828

16. Kita Y, Kimura KD, Kobayashi M et al (1998) Microinjection of activated phosphatidylinositol-3 kinase induces process outgrowth in rat PC12 cells through the Rac-JNK signal transduction pathway. J. Cell Sci. 111:907-915

17. Xiao J, Liu Y (2003) Differential roles of ERK and JNK in early and late stages of neuritogenesis: a study in a novel PC12 model system. J. Neurochem. 86:1516-1523

18. Waetzig V, Herdegen T (2003) A single c-Jun N-terminal kinase isoform (JNK3-p54) is an effector in both neuronal differentiation and cell death. J. Biol. Chem. 278:567-572

19. Brabet P, Pantaloni C, Rodriguez M et al (1990) Neuroblastoma differentiation involves the expression of two isoforms of the $\alpha$-subunit of $G_{0}$. J. Neurochem. 54:1310-1320

20. Andreopoulos S, Li PP, Warsh JJ (1995) Developmental expression of $G \alpha_{o}$ and $G \alpha_{s}$ isoforms in PC12 cells: relationship to neurite outgrowth. Develop. Brain Res. 88:3036 
21. Li X, Mumby SM, Greenwood A et al (1995) Pertussis toxin-sensitive G protein $\alpha$ subunits: production of monoclonal antibodies and detection of differential increases on differentiation of PC12 and LA-N-5 cells. J. Neurochem. 64:1107-1117

22. He JC, Gomes I, Nguyen T et al (2005) The G $\alpha_{0 / 1}$-coupled cannabinoid receptor-mediated neurite outgrowth involves Rap regulation of Src and Stat3. J. Biol. Chem. 280:3342633434

23. He JC, Neves SR, Jordan JD et al (2006) Role of the $G_{0 / i}$ signaling network in the regulation of neurite outgrowth. Can. J. Physiol. Pharmacol. 84:687-694

24. Lowes VL, Ip NY, Wong YH (2002) Integration of signals from receptor tyrosine kinases and G protein-coupled receptors. NeuroSignals 11:5-19

25. Conway AM, Rakhit S, Pyne S et al (1999) Platelet-derived-growth-factor stimulation of the p42/p44 mitogen-activated protein kinase pathway in airway smooth muscle: role of pertussis-toxin-sensitive G-proteins, c-Src tyrosine kinases and phosphoinositide 3kinase. Biochem. J. 337:171-177

26. Rakhit S, Pyne S, Pyne NJ (2000) The platelet-derived growth factor receptor stimulation of p42/p44 mitogen-activated protein kinase in airway smooth muscle involves a Gprotein-mediated tyrosine phosphorylation of Gab1. Mol. Pharmacol. 58:413-420

27. Rakhit S, Pyne S, Pyne NJ (2001) Nerve growth factor stimulation of p42/44 mitogenactivated protein kinase in PC12 cells: role of $\mathrm{G}_{\mathrm{i} / \mathrm{o}}$, $\mathrm{G}$ protein-coupled receptor kinase 2, $\beta$-arrestin 1, and endocytic processing. Mol. Pharmacol. 60:63-70

28. Tsu RC, Ho MK, Yung LY et al (1997) Role of amino- and carboxyl-terminal regions of $\mathrm{G \alpha}_{\mathrm{z}}$ in the recognition of $\mathrm{G}_{\mathrm{i}}$-coupled receptors. Mol. Pharmacol. 52:38-45

29. Kobayashi M, Nagata S, Kita Y et al (1997) Expression of a constitutively active phosphatidylinositol 3-kinase induces process formation in rat PC12 cells. Use of Cre/loxP recombination system. J. Biol. Chem. 272:16089-16092 
30. Ashcroft M, Stephens RM, Hallberg B et al (1999) The selective and inducible activation of endogenous PI3-kinase in PC12 cells results in efficient NGF-mediated survival but defective neurite outgrowth. Oncogene 18:4586-4597

31. York RD, Molliver DC, Grewal SS et al (2000) Role of phosphoinositide 3-kinase and endocytosis in nerve growth factor-induced extracellular signal-regulated kinase activation via Ras and Rap1. Mol. Cell. Biol. 20:8069-8083

32. Coleman ES, Wooten MW (1994) Nerve growth factor-induced differentiation of PC12 cells employs the PMA-insensitive protein kinase C-zeta isoform. J. Mol. Neurosci. 5:39-57

33. Wooten MW, Vandenplas ML, Seibenhener ML et al (2001) Nerve growth factor stimulates multisite tyrosine phosphorylation and activation of the atypical protein kinase C's via a src kinase pathway. Mol. Cell. Biol. 21:8414-8427

34. Ma YC, Huang J, Ali S et al (2000) Src tyrosine kinase is a novel direct effector of G proteins. Cell 102:635-646

35. Chan AS, Lai FP, Lo RK et al (2002) Melatonin mt1 and MT2 receptors stimulate c-Jun N-terminal kinase via pertussis toxin-sensitive and -insensitive G proteins. Cell. Signal. 14:249-257

36. Zapf-Colby A, Eichhorn J, Webster NJ et al (1999) Inhibition of PLC- $\gamma 1$ activity converts nerve growth factor from an anti-mitogenic to a mitogenic signal in CHO cells. Oncogene 18:4908-4919

37. Solem M, McMahon T, Messing RO (1995) Depolarization-induced neurite outgrowth in PC12 cells requires permissive, low level NGF receptor stimulation and activation of calcium/calmodulin-dependent protein kinase. J. Neurosci. 15:5966-5975 
38. Nakayama H, Numakawa T, Ikeuchi T et al (2001) Nicotine-induced phosphorylation of extracellular signal-regulated protein kinase and CREB in PC12h cells. J. Neurochem. 79:489-498

39. Ho MK, Wong $Y H$ (2001) $G_{z}$ signaling: emerging divergence from $G_{i}$ signaling. Oncogene 20:1615-1625

40. Wise A, Watson-Koken MA, Rees S et al (1997) Interactions of the $\alpha_{A}$-adrenoceptor with multiple $\mathrm{G}_{\mathrm{i}}$-family G-proteins: studies with pertussis toxin-resistant G-protein mutants. Biochem. J. 321:721-728

41. Yung, LY, Tso PH, Wu EHT et al (2008) Nerve growth factor-induced stimulation of p38 mitogen-activated protein kinase in PC12 cells is partially mediated via $\mathrm{G}_{\mathrm{i} / \mathrm{o}}$ proteins. Cell. Signal. 20:1538-1544

42. Piiper A, Dikic I, Lutz MP et al (2002) Cyclic AMP induces transactivation of the receptors for epidermal growth factor and nerve growth factor, thereby modulating activation of MAP kinase, Akt, and neurite outgrowth in PC12 cells. J. Biol. Chem. 277:43623-43630

43. Meng J, Casey PJ (2002) Activation of $G_{z}$ attenuates Rap1-mediated differentiation of PC12 Cells. J. Biol. Chem. 277:43417-43424

44. Hoshino M, Nakamura S (2003) Small GTPase Rin induces neurite outgrowth through Rac/Cdc42 and calmodulin in PC12 cells. J. Cell Biol. 163(5):1067-1076

45. Antonelli V, Bernasconi F, Wong YH et al (2000) Activation of B-Raf and regulation of the mitogen-activated protein kinase pathway by the $G_{0} \alpha$ chain. Mol. Biol. Cell $11: 1129-1142$

46. Kinane TB, Kang I, Chu A et al (1997) $\mathrm{G \alpha}_{\mathrm{i} 2}$ mediates renal LLC-PK1 growth by a Rafindependent activation of p42/p44 MAP kinase. Am. J. Physiol. 72:F273-F282

Deleted: १

42. Wu YY, Bradshaw RA (1996) Synergistic induction of neurite outgrowth by nerve growth factor or epidermal growth factor and interleukin-6 in PC12 cells. J. Biol. Chem. 271:13033-130399

43. Xing J, Kornhauser JM, Xia Z et al (1998) Nerve growth factor activates extracellular

signal-regulated kinase and p38 mitogenactivated protein kinase pathways to stimulate CREB serine 133 phosphorylation. Mol. Cell. Biol. 18:1946-1955

Deleted: 44

Deleted: 45. Vossler MR, Yao H, York RD et al (1997) cAMP activates MAP kinase and Elk-1 through a B-Raf- and Rap1dependent pathway. Cell 89:73-829

46. York RD, Yao H, Dillion T et al (1998)

Rap1 mediates sustained MAP kinase activation induced by nerve growth factor. Nature 392:622-626

Deleted: 7

Deleted: 48

Deleted: 49

Deleted: 50 
47. Lahlou H, Saint-Laurent N, Esteve JP et al (2003) sst2 Somatostatin receptor inhibits cell proliferation through Ras-, Rap1-, and B-Raf-dependent ERK2 activation. J. Biol. Chem. 278:39356-39371

48. Nagao M, Yamauchi J, Kaziro Y et al (1998) Involvement of protein kinase C and Src family tyrosine kinase in $\mathrm{G} \alpha_{\mathrm{q} / 11}$-induced activation of c-Jun N-terminal kinase and p38 mitogen-activated protein kinase. J. Biol. Chem. 273:22892-22898

49. Luttrell LM, Lefkowitz RJ (2002) The role of $\beta$-arrestins in the termination and transduction of G-protein-coupled receptor signals. J. Cell Sci. 115:455-465

50. Kam AY, Chan AS, Wong YH (2003) Rac and Cdc42-dependent regulation of c-Jun Nterminal kinases by the delta-opioid receptor. J. Neurochem. 84:503-513

51. Troppmair J, Bruder JT, App H et al (1992) Ras controls coupling of growth factor receptors and protein kinase $\mathrm{C}$ in the membrane to Raf-1 and B-Raf protein serine kinases in the cytosol. Oncogene 7:1867-1873

52. Llovera M, de Pablo Y, Egea J et al (2004) Trk is a calmodulin-binding protein: implications for receptor processing. J. Neurochem. 88:422-433

53. Agell N, Bachs O, Rocamora N et al (2002) Modulation of the Ras/Raf/MEK/ERK pathway by $\mathrm{Ca}^{2+}$ and calmodulin. Cell. Signal. 14:649-654

54. Li X, Jope RS (1997) Glucocorticoids modulate G-protein $\alpha$-subunit levels in PC12 cells. Brain Res. 759:213-220

55. Uehara T, Hoshino S, Ui M et al (1994) Possible involvement of phosphatidylinositolspecific phospholipase C related to pertussis toxin-sensitive GTP-binding proteins during adipocyte differentiation of 3T3-L1 fibroblasts: negative regulation of protein kinase C. Biochimica et Biophysica Acta 1224:302-310

56. Watkins DC, Johnson GL, Malbon CC (1992) Regulation of the differentiation of teratocarcinoma cells into primitive endoderm by $\mathrm{G} \alpha_{\mathrm{i} 2}$. Science 258:1373-1375
Deleted: 51

Deleted : 52. Zhong H, Minneman KP (1999) Activation of tyrosine kinases by $\alpha_{1 \mathrm{~A}^{-}}$ adrenergic and growth factor receptors in transfected PC12 cells. Biochem. J. 344:889 894 9

53. Malek RL, Nie Z, Ramkumar V et al (1999) Adenosine $A_{2 A}$ receptor mRNA regulation by nerve growth factor is TrkA-,

Src-, and Ras-dependent via extracellular regulated kinase and stress-activated protein kinase/c-Jun $\mathrm{NH}_{2}$-terminal kinase. J. Biol. Chem. 274:35499-35504ף

Deleted: 55

Deleted: 56

Deleted: 57

Deleted: 58

Deleted: 59

Deleted: 60

Deleted: 61

Deleted: 62 
57. Ogier-Denis E, Petiot A, Bauvy C et al (1997) Control of the expression and activity of the Go-interacting protein (GAIP) in human intestinal cells. J. Biol. Chem. 272:24599-24603

58. Aoki K, Nakamura T, Matsuda M (2004) Spatio-temporal regulation of Rac1 and Cdc42 activity during nerve growth factor-induced neurite outgrowth in PC12 cells. J. Biol. Chem. 279:713-719

59. Yamauchi J, Tsujimoto G, Kaziro Y et al (2001) Parallel regulation of mitogen-activated protein kinase kinase 3 (MKK3) and MKK6 in $\mathrm{G}_{q}$-signaling cascade. J. Biol. Chem. 276:23362-23372

60. Luttrell LM, Kilgour E, Larner J et al (1990) A pertussis toxin-sensitive G-protein mediates some aspects of insulin action in BC3H-1 murine myocytes. J. Biol. Chem. 265: $16873-16879$

61. Moughal NA, Waters CM, Valentine WJ et al (2006) Protean agonism of the lysophosphatidic acid receptor-1 with Ki16425 reduces nerve growth factorinduced neurite outgrowth in PC12 cells. J. Neurochem. 98:1920-1929

62. Wu EHT, Wong YH (2005) Pertussis toxin-sensitive $\mathrm{G}_{\mathrm{i} / \mathrm{o}}$ proteins are involved in nerve growth factor-induced pro-survival Akt signaling cascade in PC12 cells. Cell. Signal. $17: 881-890$

63. Wu EHT, Wong YH (2006) Activation of muscarinic $\mathrm{M}_{4}$ receptor augments NGF-induced pro-survival Akt signaling in PC12 cells. Cell. Signal. 18:285-293

64. Luttrell LM, Van Biesen T, Hawes BE et al (1995) G subunits mediate mitogen-activated protein kinase activation by the tyrosine kinase insulin-like growth factor 1 receptor. J. Biol. Chem. 270:16495-16498

65. Hallak H, Seiler AEM, Green JS et al (2000) Association of heterotrimeric $\mathrm{G}_{\mathrm{i}}$ with the insulin-like growth factor-I receptor. Release of G subunits upon receptor activation.
Deleted: 63

Deleted: 64

Deleted: 65

Deleted: 66

Deleted: 67

Deleted: 68

Deleted: 69

Deleted: 70

Deleted: 71 
J. Biol. Chem. 275:2255-2258

66. Booth RA, Cummings C, Tiberi M et al (2002) GIPC participates in G protein signaling downstream of insulin-like growth factor 1 receptor. J. Biol. Chem. 277:6719-6725

67. Lou X, Yano H, Lee F et al (2001) GIPC and GAIP form a complex with TrkA: a putative link between $\mathrm{G}$ protein and receptor tyrosine kinase pathways. Mol. Biol. Cell 12:615627

68. Wang LH, Kalb RG, Strittmatter SM (1999) A PDZ protein regulates the distribution of the transmembrane semaphorin, M-SemF. J. Biol. Chem. 274:14137-14146

69. Liu Z, Chatterjee TK, Fisher RA (2002) RGS6 interacts with SCG10 and promotes neuronal differentiation. Role of the Gy subunit-like (GGL) domain of RGS6 J. Biol. Chem. 277: 37832-37839

70. Alderton F, Rakhit S, Kong KC et al (2001) Tethering of the platelet-derived growth factor beta receptor to G-protein-coupled receptors. A novel platform for integrative signaling by these receptor classes in mammalian cells. J. Biol. Chem. 276:2857828585

71. McDonald PH, Chow C-W, Miller WE et al (2000) $\beta$-Arrestin 2: A receptor-regulated MAPK scaffold for the activation of JNK3. Science 290:1574-1577

72. Wu EHT, Wu KKH, Wong YH (2007) Tuberin: a stimulus-regulated tumor suppressor protein controlled by a diverse array of receptor tyrosine kinases and G proteincoupled receptors. NeuroSignals 15:217-227

73. New DC, Wong YH (2007) Molecular mechanisms mediating the G protein-coupled receptor regulation of cell cycle progression. J. Mol. Signal 2:2

74. New DC, Wu KKH, Kwok AWS, Wong YH (2007) G protein-coupled receptor-induced $\underline{\text { Akt activity in cellular proliferation and apoptosis. FEBS J 274:6025-6036 }}$
Deleted: 72

Deleted: 73

Deleted: 74

Deleted: 75

Deleted: 76 
Deleted: 77

Opin. Neurobiol. 11:272-280

Deleted: ๆ 
Figure 1. NGF induced JNK phosphorylation in PC12 cells. A. PC12 cells were seeded at 10,000 cells/well into $35 \mathrm{~mm}$ plates in $2 \mathrm{ml}$ assay medium (0.1\% FCS/DMEM). Subsequently, the cells were treated with $5 \mathrm{ng} / \mathrm{ml}$ NGF in the absence or presence of an inhibitor (10 $\mu \mathrm{M}$ SB202190, $10 \mu \mathrm{M}$ U1026 or $10 \mu \mathrm{M}$ SP600125) as indicated; growth medium and inhibitors were replaced every 2 days. Micrographs of PC12 cells were taken with a light microscope $(40 \mathrm{X})$ on day 10 . B. PC12 cells were treated as in A and measurements of neurite length $(\mu \mathrm{m})$ were determined from the micrographs of PC12 cells. *NGF significantly stimulated neurite extension (Dunnett $t$ test, $P<0.05$ ). Values are the mean \pm S.E. from the neurite protrusions of 50 cells. C. PC12 cells were seeded into 12-well plate and then grown in reduced serum $(0.1 \%$ FCS $)$ for $24 \mathrm{~h}$ on the second day. The cells were subsequently challenged with $1 \mathrm{ml}$ serum free medium containing 5 or $50 \mathrm{ng} / \mathrm{ml}$ NGF for different time durations as indicated. PC12 cells were treated with $5 \mathrm{ng} / \mathrm{ml}$ (solid circle) or 50 ng/ml (open circle) of NGF. D. PC12 cells were treated as in C but with varying concentrations of NGF for $10 \mathrm{~min}$. For $\mathbf{C}$ and $\mathbf{D}$, the cell lysates were analyzed for JNK phosphorylation as described in Experimental Procedure. Values are the mean \pm S.E. from three separate experiments while only representative Western blots are shown. 
Figure 2. NGF-induced JNK phosphorylation employed p38 MAPK and ERK1/2. A. PC12 cells were treated as in the legend to Fig. 1C in the absence or presence of a specific inhibitor (24 $\mu \mathrm{M} 420123$ or $10 \mu \mathrm{M}$ SP600125) as indicated for $15 \mathrm{~min}$ and subsequently stimulated with $5 \mathrm{ng} / \mathrm{ml}$ NGF for 10 min. Cell lysates were analyzed for JNK phosphorylation. B. PC12 cells were treated with respective inhibitors $(10 \mu \mathrm{M}$ U0124, $10 \mu \mathrm{M}$ U0126, $10 \mu \mathrm{M}$ SB202190, $10 \mu \mathrm{M}$ SB203580 or $10 \mu \mathrm{M}$ Raf-1 inhibitor) as in A before assaying JNK phosphorylation. *NGF significantly stimulated JNK phosphorylation (Dunnett $t$ test, $P<0.05)$. "NGF-induced JNK phosphorylation was significantly suppressed by the respective inhibitors (Dunnett $t$ test, $P<0.05$ ). Values are the mean \pm S.E. from three separate experiments while only representative Western blots are shown. 
Figure 3. NGF-regulated JNK activity employed c-Src, but not PI3K/Akt signaling. A. PC12 cells were treated as in the legend to Fig. 2 in the absence or presence of a specific inhibitor (10 $\mu \mathrm{M}$ KN62, $50 \mathrm{nM}$ W7, $10 \mu \mathrm{M}$ AG1295, 100 nM wortmannin, $10 \mu \mathrm{M}$ U73122, $10 \mu \mathrm{M}$ U73343 or $200 \mathrm{nM}$ staurosporine) before assaying for JNK phosphorylation. B. PC12 cells were treated as in the legend to $\mathbf{A}$ in the absence or presence of various inhibitors (10 $\mu \mathrm{M}$ WHI-P131, $10 \mu \mathrm{M}$ WHI-P258, $5 \mu \mathrm{M}$ SU6656, $25 \mu \mathrm{M}$ PP1, $25 \mu \mathrm{M}$ PP2 or $25 \mu \mathrm{M}$ PP3) before assaying for JNK phosphorylation. *NGF significantly stimulated JNK phosphorylation (Dunnett $t$ test, $P<0.05$ ). "NGF-induced JNK phosphorylation was significantly inhibited by inhibitors (Dunnett $t$ test, $P<0.05$ ). Values are the mean \pm S.E. from three separate experiments while only representative Western blots are shown. C. PC12 cells were treated as in the legend to Fig. 1A, in the absence or presence of an inhibitor $(10 \mu \mathrm{M}$ WHI-P131 or $25 \mu \mathrm{M}$ PP1) as indicated. Micrographs of PC12 cells were taken with a light microscope (40 X) on day 10. D. PC12 cells were treated as in C and measurements of neurite length $(\mu \mathrm{m})$ were determined from the micrographs. *NGF significantly stimulated neurite extension (Dunnett $t$ test, $P<0.05$ ). Values are the mean \pm S.E. from the neurite protrusions of 50 cells. 
Figure 4. NGF-induced JNK phosphorylation involves $\mathrm{G}_{\mathrm{i} / \mathrm{o}}$ proteins. A. PC12 cells were seeded into 12 -well plates and then cultured in reduced serum $(0.1 \%$ FCS $)$ with or without PTX (100 ng/ml) for $24 \mathrm{~h}$. PC12 cells were stimulated with $1 \mathrm{ml}$ assay medium containing 5 ng/ml NGF for $10 \mathrm{~min}$. Cell lysates were analyzed for JNK phosphorylation. *NGF significantly stimulated JNK phosphorylation (Dunnett $t$ test, $P<0.05$ ). ${ }^{\#}$ NGF-induced JNK phosphorylation was significantly inhibited by PTX (Dunnett $t$ test, $P<0.05$ ). Values are the mean \pm S.E. from three separate experiments while only representative Western blots are shown. B. Primary cortical neuron cultures at DIV7 were seeded into 6-well plates and then replenished with the growth medium without B27 supplement in the presence or absence of $\underline{\text { PTX }(100 \mathrm{ng} / \mathrm{ml}) \text { for } 24 \mathrm{~h} \text {. The cultures were then stimulated with } 5 \mathrm{ng} / \mathrm{ml} \text { NGF for } 15 \mathrm{~min}}$ and their cell lysates analyzed for JNK phosphorylation. C and D. PC12 cells were seeded into 12-well plate and transfected with cDNAs encoding $G \alpha_{z}, G \alpha_{o A}, G \alpha_{o A} C I, G \alpha_{i 2}, G \alpha_{i 2 z}$, $\mathrm{G} \alpha_{\mathrm{i} 1}, \mathrm{G} \alpha_{\mathrm{i} 1} \mathrm{CI}, \mathrm{G} \alpha_{\mathrm{i} 3}$, or $\mathrm{G} \alpha_{\mathrm{i} 3} \mathrm{CI}$ as indicated. Transfected PC12 cells were susbsequently treated as in $\mathbf{A}$ and challenged with $5 \mathrm{ng} / \mathrm{ml} \mathrm{NGF}$ for $10 \mathrm{~min}$. Cell lysates were analyzed for JNK phosphorylation. *NGF significantly stimulated JNK phosphorylation (Dunnett $t$ test, $P<0.05) .{ }^{~}$ NGF-induced JNK phosphorylation was significantly reduced by PTX treatment (Dunnett $t$ test, $P<0.05$ ). Values are the mean \pm S.E. from three separate experiments while only representative Western blots are shown. 